\title{
Effects of Risperidone on the Peripheral Noradrenegic System in Patients with Schizophrenia: A Comparison with Clozapine and Placebo
}

Igor Elman, M.D., David S. Goldstein, M.D., Ph.D., Alan I. Green, M.D., Graeme Eisenhofer, Ph.D., Carol J. Folio, R.N., Courtney S. Holmes, M.S., David Pickar, M.D., and Alan Breier

Risperidone is an atypical antipsychotic drug that increases plasma norepinephrine (NE) levels, but the mechanism behind this effect is unclear. We measured arterial plasma levels of NE and other catechols during intravenous infusion of tritium-labeled $N E\left({ }^{3} \mathrm{H}-\mathrm{NE}\right)$ in risperidonetreated patients and compared their data with those from patients treated with clozapine or placebo. NE levels in risperidone patients were significantly higher than in placebo patients, but lower than in clozapine patients. Neither drug, however, had significant effect on plasma levels of the main neuronal metabolite of NE, dihydroxyphenylglycol (DHPG), suggesting that adrenoceptors blockade alone would not explain the NE findings. The rate of release of endogenous NE into the bloodstream (spillover) was elevated in both risperidone and clozapine patients in a manner that paralleled their NE levels; the NE clearance in both groups did not differ from placebo. Following ${ }^{3} \mathrm{H}-\mathrm{NE}$ infusion in risperidone-treated individuals, production of ${ }^{3} \mathrm{H}-\mathrm{DHPG}$ was normal, as it was in the clozapine group, suggesting that risperidone does not impede neuronal uptake or intraneuronal metabolism of $N E$ by monoamine oxidase. Our data suggest that both risperidone and clozapine elevate plasma NE levels via enhanced neurotransmitter spillover, with risperidone producing a smaller effect.

[Neuropsychopharmacology 27:293-300, 2002] (C) American College of Neuropsychopharmacology. Published by Elsevier Science Inc.
From the Department of Psychiatry, Massachusetts General Hospital, Boston, MA (IE); Commonwealth Research Center, Boston, MA (AIG); Harvard Medical School, Boston, MA (IE, AIG); Clinical Neurocardiology Section, National Institute of Neurological Disorders and Stroke, National Institutes of Health, Bethesda, MD (DSG, GE, CJF, CSH); Comprehensive NeuroScience Inc., Washington, DC (DP); Lilly Research Laboratories, Indianapolis, IN (AB); and Department of Psychiatry, Indiana University School of Medicine, Indianapolis, IN (AB).

Address correspondence to: Igor Elman, M.D., Department of Psychiatry, Massachusetts General Hospital, Harvard Medical School, 15 Parkman St WACC-812, Boston, MA 02114, Tel: (617) 724-9385, Fax: (617) 248-0070, E-mail: elman.igor@mgh.harvard.edu

Received October 11, 2001; revised February 14, 2002; accepted February 20, 2002.

Online publication: 2/28/02 at www.acnp.org/citations/ Npp022802255.
KEY WORDS: Schizophrenia; Catecholamine; Spillover; Clearance; DHPG; Tritium-labeled norepinephrine

Clozapine is an atypical antipsychotic drug (APD) with efficacy superior to that of conventional agents and with little or no extrapyramidal signs or symptoms (EPS) (Kane et al. 1988; Lieberman et al. 1989; Breier et al. 1994a; Meltzer 1995; Meltzer et al. 1996). Because these advantageous therapeutic properties are accompanied by unusually severe side effects, scientists have been searching for clozapine-like APDs that would share its beneficial features but not induce bone marrow toxicity, seizures, or hypotension. This search has resulted in the introduction of four "newer atypical APDs" (i.e., risperidone, 
olanzapine, quetiapine, and ziprasidone), all of which have important effects on both dopaminergic and serotonergic neurotransmitter systems. Because none of these compounds has been proven as efficacious as the prototype, clozapine, in the treatment of resistant cases, continued research is focusing on other neurotransmitter systems affected by clozapine.

Clozapine profoundly increases norepinephrine (NE) levels in both CSF (Ackenheil 1989; Lieberman et al. 1989; Lieberman et al. 1991; Pickar et al. 1992) and plasma (Pickar et al. 1992; Green et al. 1993; Davidson et al. 1993; Breier 1994; Breier et al. 1994b; Schulz et al. 1996; Schulz et al. 1997; Brown et al. 1997; Fleischhaker et al. 1998; Elman et al. 1999), an effect not seen with typical APDs. In some (Breier et al. 1994b; Schulz et al. 1997; Fleischhaker et al. 1998), but not all (Brown et al. 1997) studies, plasma NE increases have been related to clinical improvement, suggesting that this pharmacological effect may play a role in clozapine's beneficial central actions. In this context, findings implicating noradrenergic dysregulation in the pathophysiology of schizophrenia (Stein and Wise 1971; Sternberg 1984; Breier et al. 1990; Rao and Moller 1994; Breier 1994; Yamamoto et al. 1994; Litman et al. 1996; Breier et al. 1998; Goff and Evins 1998; Friedman et al. 1999a; Friedman et al. 1999b; Klimek et al. 1999) further support inquiry into the relevance of noradrenergic mechanisms in the action of APDs.

We have reported previous data suggesting that high plasma NE levels in clozapine-treated patients result from increases in the appearance rate of the endogenously released NE in the plasma (spillover) rather than from decreased neuronal uptake of NE, inhibition of intraneuronal monoamine oxidase (MAO), or adrenoceptor antagonism (Elman et al. 1999). Risperidone, the next atypical antipsychotic drug marketed in the United States after clozapine, is associated with a low incidence of EPS and may have improved efficacy compared with conventional agents (Kane and McGlashan 1995; Pickar 1995; Campbell et al. 1999). Interestingly, risperidone has also recently been observed in a clinical study to produce a modest (i.e., $58 \%$ ) increase in plasma NE levels (See et al. 1999), thus extending the phenomenon of NE elevations to another atypical APD.

Although both risperidone and clozapine appear to share an ability to produce elevations of plasma NE, there are striking differences in their neurochemical properties. Even though both agents have a high serotonin $5 \mathrm{HT}_{2 \mathrm{~A}}$-to-dopamine $\mathrm{D}_{2}$ binding ratio (a characteristic shared by most atypicals), risperidone has two orders of magnitude higher affinity for both of these receptors than does clozapine; it also has a substantially higher affinity for $\alpha_{1}$ and $\alpha_{2}$ adrenoceptors than does clozapine (Schotte et al. 1993; Breier et al. 1999; Richelson 1999). Also, among atypical APDs, risperidone has the simplest binding profile and clozapine has the most broad-spectrum one (Stahl 2000).
The differences in the receptor binding profiles of these two compounds led us to wonder whether the reportedly modest NE elevation produced by risperidone (See et al. 1999) was generated by the same mechanism that results in a profound (i.e., 200-400\%) NE elevation in patients treated with clozapine. To explore this issue, we applied a comprehensive neuropharmacological approach that includes intravenous infusion of tracer amounts of tritium-labeled NE $\left({ }^{3} \mathrm{H}-\mathrm{NE}\right)$ in schizophrenic patients treated with risperidone. Because formation of ${ }^{3} \mathrm{H}$-dihydroxyphenylglycol (DHPG) from ${ }^{3} \mathrm{H}$ $\mathrm{NE}$ requires both neuronal uptake and intraneuronal deamination by $\mathrm{MAO}$, measurement of plasma ${ }^{3} \mathrm{H}-$ DHPG responses furnished the basis for examining the effects of risperidone. Plasma levels of the NE precursor, dihydroxyphenylalanine (DOPA), and of the dopamine metabolite, dihydroxyphenylacetic acid (DOPAC), were also measured to provide information about NE synthesis (Goldstein et al. 1987; Goldstein 1995) and about intraneuronal metabolism by monoamine oxidase (MAO; Goldstein 1995).

Our previous work suggested that clozapine has complex effects on the noradrenergic system, producing a robust increase in NE, but without an expected proportional increase in DHPG (Breier et al. 1994b; Elman et al. 1999). We hypothesized, based on the receptor binding profile of risperidone, that patients treated with the drug would display different characteristics of the noradrenergic response than their clozapine-treated counterparts. Specifically, risperidone's very potent antagonism at the $\alpha_{1}$ and $\alpha_{2}$ adrenoceptors (Schotte et al. 1993; Richelson 1999) was expected to increase sympathetic outflow, caused by vasodilatation (from $\alpha_{1}$ effects) and blockade of inhibitory $\alpha_{2}$ adrenoceptors on sympathetic nerves, thus producing high NE spillover. This would be combined with heightened intraneuronal NE metabolism and production of DHPG, as adrenoceptor blockade usually produces increases in DHPG plasma levels that parallel the NE increases (Breier 1994; Goldstein 1995).

\section{MATERIALS AND METHODS}

\section{Subjects}

Eight risperidone-, twelve clozapine- and six placebotreated patients with schizophrenia who participated in this research protocol were enrolled in the double blind, parallel group comparative efficacy study of the effects of risperidone and clozapine (Breier et al. 1999) at the Section on Clinical Studies, National Institutes of Health (NIH) Clinical Center, Bethesda, MD. Data from clozapine- and placebo-treated patients have been previously reported (Elman et al. 1999) and are included in this article to allow for comparison with the risperidone effects. All subjects gave written informed consent to 
participate in the protocol, which was approved by the NIH IRB. All subjects were in good physical health as evidenced by physical examination, ECG, and screening blood tests. Patients with concurrent drug abuse, alcoholism, organic brain disorder, mental retardation, or a medical condition that contraindicates use of risperidone or clozapine were excluded from the study. The treatment groups did not differ in demographic or clinical characteristics (Table 1). The patients were on a stable dose of medication or placebo for a 2-week minimum prior to the study; they did not receive other medications. Doses had been varied to achieve maximal clinical efficacy (risperidone mean dose \pm SD: $3.9 \pm 1.9 \mathrm{mg}$ per day; clozapine mean dose \pm SD: $390.0 \pm 188.3 \mathrm{mg}$ per day).

\section{Procedure}

The subjects were studied at 9 am after having fasted and refrained from alcohol, tobacco, caffeine, or physical activity for at least $10 \mathrm{~h}$. With the patient in supine position, an arterial catheter was inserted percutaneously after local anesthesia of the overlying skin. An antecubital IV catheter was inserted into the contralateral arm. After $60 \mathrm{~min}$ of resting, ${ }^{3} \mathrm{H}-\mathrm{NE}\left(\left[1,7-{ }^{3} \mathrm{H}\right] \mathrm{NE}, 14-22\right.$ $\mathrm{Ci} / \mathrm{mmol}$; New England Nuclear, Boston, MA) in $50 \mathrm{ml}$ normal saline was infused intravenously at $0.75 \mathrm{ml} /$ min. Arterial blood samples $(7-8 \mathrm{ml})$ were obtained at $15,30,45$, and 60 min after the ${ }^{3} \mathrm{H}-\mathrm{NE}$ infusion began.

\section{Biochemical Variables}

Blood for assays was collected in heparinized tubes and placed on wet ice. After separation by refrigerated centrifugation, the plasma was stored at $-80^{\circ} \mathrm{C}$. Plasma catechol levels were assayed using liquid chromatography with electrochemical detection (Eisenhofer et al. 1986). Concentrations of ${ }^{3} \mathrm{H}-\mathrm{NE}$ and ${ }^{3} \mathrm{H}-\mathrm{DHPG}$ were measured by scintillation spectrometry on effluent from the chromatographic column (Eisenhofer et al. 1991). Interassay coefficients of variation were $6.5 \%$ for NE, $3.9 \%$ for ${ }^{3} \mathrm{H}-\mathrm{NE}, 8.4 \%$ for DHPG, $4.7 \%$ for ${ }^{3} \mathrm{H}-\mathrm{DHPG}, 5.9 \%$ for DOPA, and $11.6 \%$ for DOPAC. Intra-assay coefficients of variations were $1.9 \%$ for $\mathrm{NE}, 3.2 \%$ for ${ }^{3} \mathrm{H}-\mathrm{NE}, 3.7 \%$ for DHPG, $7.6 \%$ for ${ }^{3} \mathrm{H}-\mathrm{DHPG}, 3.8 \%$ for DOPA, and $3.9 \%$ for DOPAC.

The rate of release of endogenous NE into arterial plasma and the rate of clearance from plasma was determined with the following equations: 1$) \mathrm{CL}=\mathrm{IR} /\left[{ }^{3} \mathrm{H}\right]-\mathrm{NE}$ and 2) $\mathrm{SP}=\mathrm{CLxNEa}$; where $\mathrm{CL}$ is the arterial plasma $\mathrm{NE}$ clearance $(\mathrm{ml} / \mathrm{min})$, IR is the infusion rate of $\left[{ }^{3} \mathrm{H}\right]-\mathrm{NE}$, $\left[{ }^{3} \mathrm{H}\right]-\mathrm{NE}$ is the arterial plasma concentration of $\left[{ }^{3} \mathrm{H}\right]-\mathrm{NE}$, $\mathrm{SP}$ is the NE spillover rate $(\mathrm{pmol} / \mathrm{min})$ into arterial plasma, and NEa is the arterial plasma concentration of endogenous NE (Esler et al. 1979). Neuronal uptake (Eisenhofer et al. 1991) and NE stores at the active release sites (Eisenhofer et al. 1991; Eisenhofer et al. 1996) were assessed from the ${ }^{3} \mathrm{H}-\mathrm{DHPG}$ and ${ }^{3} \mathrm{H}-\mathrm{NE}$ concentrations.

\section{Statistical Analyses}

The data were analyzed using Statistica (StatSoft, Inc., Tulsa OK). Because no time-related changes were expected for the non tritium-labeled neurochemicals, their measurements across the four sampling points were averaged and expressed as means \pm standard deviation (SD). Differences among the treatment groups were assessed by one-way analysis of variance (ANOVA), with drug condition (risperidone, clozapine, and placebo) as the grouping factor. When a group effect was significant, post-hoc $t$-tests were performed. Time-related trends in ${ }^{3} \mathrm{H}-\mathrm{DHPG} /{ }^{3} \mathrm{H}-\mathrm{NE}$ ratios were examined by repeated-measures ANOVAs, with drug condition as the grouping factor and time as the within-subjects factor. A p value of less than 0.05 defined statistical significance. All tests were two-tailed.

\section{RESULTS}

\section{Catechol Levels}

Both risperidone- and clozapine-treated groups had elevated plasma NE levels, averaging respectively almost two and four times higher than the placebo-treated group $(\mathrm{F}=9.89 ; \mathrm{df}=2,23 ; p<.001$; Figure 1$)$. Post-hoc $t$-tests revealed significantly lower NE levels in risperidone- versus clozapine-treated $(\mathrm{t}=-2.64 ; \mathrm{df}=18 ; p=.02)$ patients, and significantly higher NE levels in risperidone- versus

Table 1. Demographic and Clinical Characteristics of Schizophrenic Patients Treated with Clozapine, Risperidone, and Placebo.

\begin{tabular}{lcccc}
\hline Patient Characteristic & Clozapine & Risperidone & Placebo & F (df= 2,23); p \\
\hline Age (years) & $36.0(8.4)$ & $37.9(9.7)$ & $42.7(4.7)$ & $1.32 ; 0.29$ \\
Sex (M/F) & $10 / 2$ & $7 / 1$ & $4 / 2$ & - \\
Age of onset (years) & $21.6(4.3)$ & $23.9(7.4)$ & $27.8(6.0)$ & $2.34 ; 0.12$ \\
No. of hospitalizations & $5.3(7.5)$ & $7.5(4.6)$ & $2.7(2.4)$ & $1.35 ; 0.28$ \\
\hline
\end{tabular}

Data are presented as mean (SD).

Clozapine $(\mathrm{N}=12)$; risperidone $(\mathrm{N}=8)$; placebo $(\mathrm{N}=6)$. 

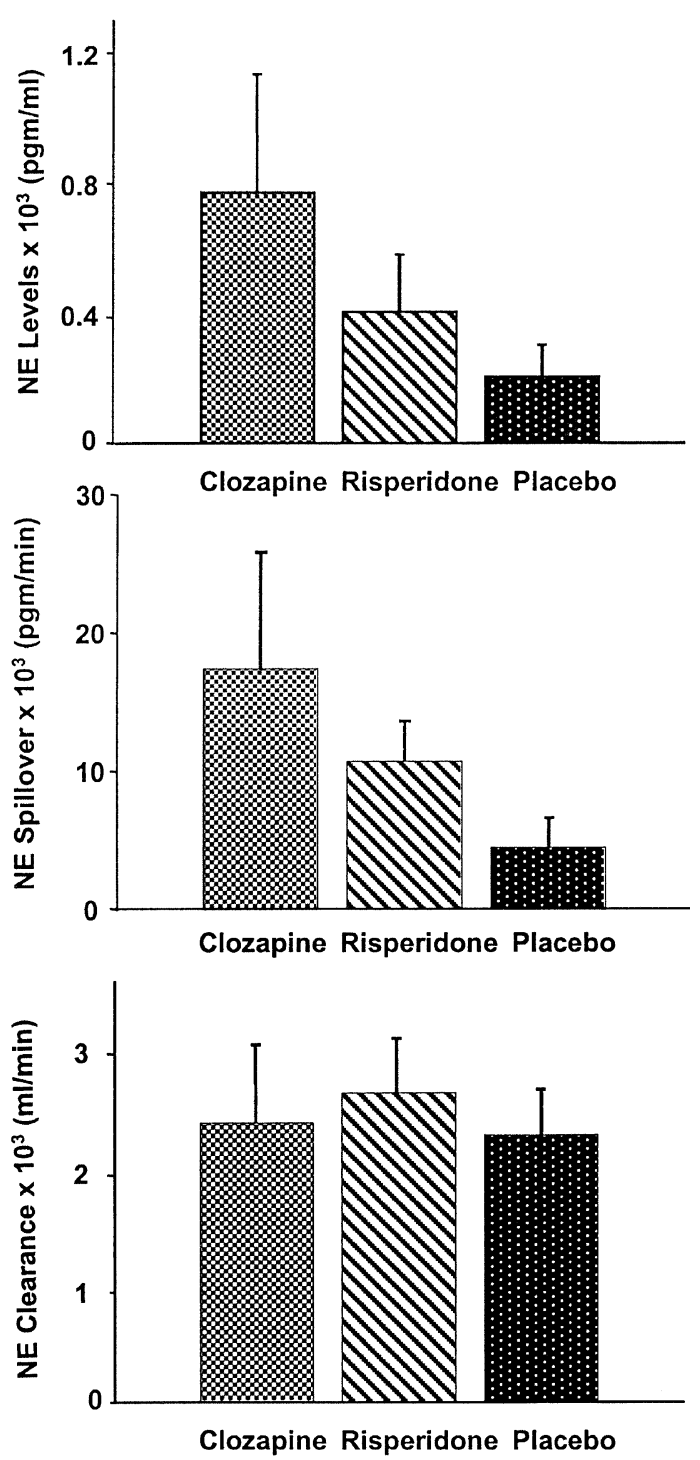

Figure 1. NE plasma level, NE spillover, and NE clearance in schizophrenic patients treated with clozapine $(\mathrm{n}=12)$, risperidone $(n=8)$, and placebo $(n=6)$. Data are presented as mean \pm SD. Statistical differences were determined using a oneway analysis of variance (ANOVA) with drug condition (risperidone, clozapine, and placebo) as the grouping factor and post-hoc $t$-tests. Significant effect for both plasma NE levels $(\mathrm{F}=9.89 ; \mathrm{df}=2,23 ; p<.001)$ and $\mathrm{NE}$ spillover $(\mathrm{F}=9.65$; $\mathrm{df}=2,23 ; p=.001)$, but not for $\mathrm{NE}$ clearance $(\mathrm{F}=0.87 ; \mathrm{df}=2,23 ; p=$ .43). Significantly lower NE levels in risperidone- vs. clozapinetreated $(\mathrm{t}=-2.64 ; \mathrm{df}=18 ; p=.02)$ patients, and significantly higher NE levels in risperidone- vs. placebo-treated $(t=2.64$; $\mathrm{df}=12 ; p=.02$ ) individuals. Significantly lower NE spillover values in risperidone- vs. clozapine-treated $(\mathrm{t}=-2.37$; $\mathrm{df}=18 ; p=.03$ ) group, and significantly higher values in risperidone- vs. placebo-treated $(\mathrm{t}=3.91 ; \mathrm{df}=12 ; p<.01)$ group.

placebo-treated $(\mathrm{t}=2.64 ; \mathrm{df}=12 ; p=.02)$ individuals. Mean plasma DHPG levels were $24 \%$ higher (trend significance; $\mathrm{t}=1.72 ; \mathrm{df}=18 ; p=.1)$ in risperidone- versus clozapinetreated patients and $15 \%$ higher (not significant) in ris- peridone- versus placebo-treated patients (Table 2). The groups did not differ in plasma levels of DOPA and DOPAC.

\section{NE Spillover}

There was a significant drug condition effect on NE spillover $(\mathrm{F}=9.65 ; \mathrm{df}=2,23 ; p=.001$; Figure 1). Post-hoc $t$-tests revealed significantly lower NE spillover values in risperidone- versus clozapine-treated $(\mathrm{t}=-2.37 ; \mathrm{df}=18 ; p=$ $.03)$ group and significantly higher values in risperidoneversus placebo-treated $(\mathrm{t}=3.91 ; \mathrm{df}=12 ; p<.01)$ group.

\section{NE Clearance}

The three treatment groups did not differ in plasma NE clearance $(\mathrm{F}=0.87 ; \mathrm{df}=2,23 ; p=.43$; Figure 1$)$.

\section{Time-Related Trends in ${ }^{3} \mathrm{H}-\mathrm{DHPG} /{ }^{3} \mathrm{H}-\mathrm{NE}$ Ratio}

${ }^{3} \mathrm{H}-\mathrm{DHPG} /{ }^{3} \mathrm{H}-\mathrm{NE}$ ratios increased progressively with time $(\mathrm{F}=12.72 ; \mathrm{df}=3,69 ; p<.0001)$. The increases did not differ among the groups, as indicated by a statistically non-significant interaction effect for group with time $(\mathrm{F}=0.09 ; \mathrm{df}=3,69 ; p=1.0$; Figure 2$)$.

\section{DISCUSSION}

In this study, risperidone produced substantial increases in arterial plasma NE levels, reflecting enhanced NE spillover. Furthermore, our data show that risperidone differs from clozapine in some of its noradrenergic effects. Risperidone-treated patients displayed plasma NE concentrations that were lower than those of clozapine- but higher than placebo-treated patients. By contrast, the DHPG levels of risperidone patients were actually $24 \%$ higher (trend significance) as compared with patients on clozapine. On the other hand, as with clozapine, risperidone did not alter DOPA and DOPAC levels, or the time-related changes in the ${ }^{3} \mathrm{H}-\mathrm{DHPG} /{ }^{3} \mathrm{H}-\mathrm{NE}$ ratio following ${ }^{3} \mathrm{H}-\mathrm{NE}$ infusion.

Although some prior clinical studies support the noradrenergic system's involvement in the treatment response to clozapine (Breier et al. 1994b; Schulz et al. 1997; Fleischhaker et al. 1998), no such data are available for risperidone (See et al. 1999), and no inferences can be made about risperidone's therapeutic mechanisms of action from this investigation that was primarily focused on its pharmacokinetic effects. Nonetheless, peripheral NE measures are important because a considerable amount of animal data, where peripheral and central measures were collected simultaneously in the presence of an effective blood-brain barrier, suggest that plasma measures may reflect directionally similar changes in the brain (Ziegler et al. 1977; Jimerson et al. 
Table 2. Arterial Plasma Catechol Levels ( $\mathrm{pgm} / \mathrm{ml}$ ) in Schizophrenic Patients Treated with Clozapine, Risperidone, and Placebo.

\begin{tabular}{lrrrr}
\hline Catechol & Clozapine & Risperidone & \multicolumn{1}{c}{ Placebo } & F (df=2,23); p \\
\hline DHPG & $727.85(172.89)$ & $903.72(286.71)$ & $783.88(186.78)$ & $1.59 ; 0.22$ \\
DOPA & $1527.19(271.27)$ & $1407.47(344.56)$ & $1403.79(282.70)$ & $0.54 ; 0.59$ \\
DOPAC & $1104.08(224.21)$ & $1238.91(484.83)$ & $1398.92(532.10)$ & $1.13 ; 0.34$ \\
\hline \multicolumn{2}{l}{ Data are presented as mean (SD). } \\
\multicolumn{2}{l}{ Clozapine (N = 12); risperidone (N = 8); placebo $(\mathrm{N}=6)}$.
\end{tabular}

1981; Lambert et al. 1997; Esler et al. 1998; Tjurmina et al. 1999). Hence, changes in plasma NE in risperidonetreated patients may suggest analogous changes in the patients' brain (Breier 1994; Breier et al. 1994b; Brown et al. 1997). In addition, peripheral effects of NE alone could be hypothesized to contribute to potential adverse outcomes. For instance, given preclinical (Nagai et al. 1995) and clinical (Walters et al. 1997) evidence suggesting NE's anti-insulin activity, this effect may be involved in the development of diabetic ketoacidosis reported during treatment with both atypical agents (Colli et al. 1999; Croarkin et al. 2000).

Our findings are consistent with the previous report of risperidone-induced plasma NE elevations (See et al. 1999). The almost two-fold increase that we noted was unexpected, given that the previous study found modest increases that averaged 58\% (See et al. 1999). Direct comparison between See et al. (1999) and our study, however, is complicated by methodological differences. The former study (See et al. 1999) involved within group comparison of NE levels from blood; our study used between group comparison of arterial plasma NE levels. In particular, the differences in the source of the NE sample may be crucial because NE concentrations in antecubital venous blood may be unreliable indicators of total body sympathetic nervous activity (Folkow et al. 1983). An advantage of arterial sampling is independence from local peripheral metabolism and blood flow, as suggested by studies demonstrating that tissues of the arm remove a substantial proportion of the radioactively-labeled NE in the arterial plasma (Chang et al. 1986).

Even though our previous study showed that $\alpha_{2}$ blockade alone would not explain the patterns of cloza-

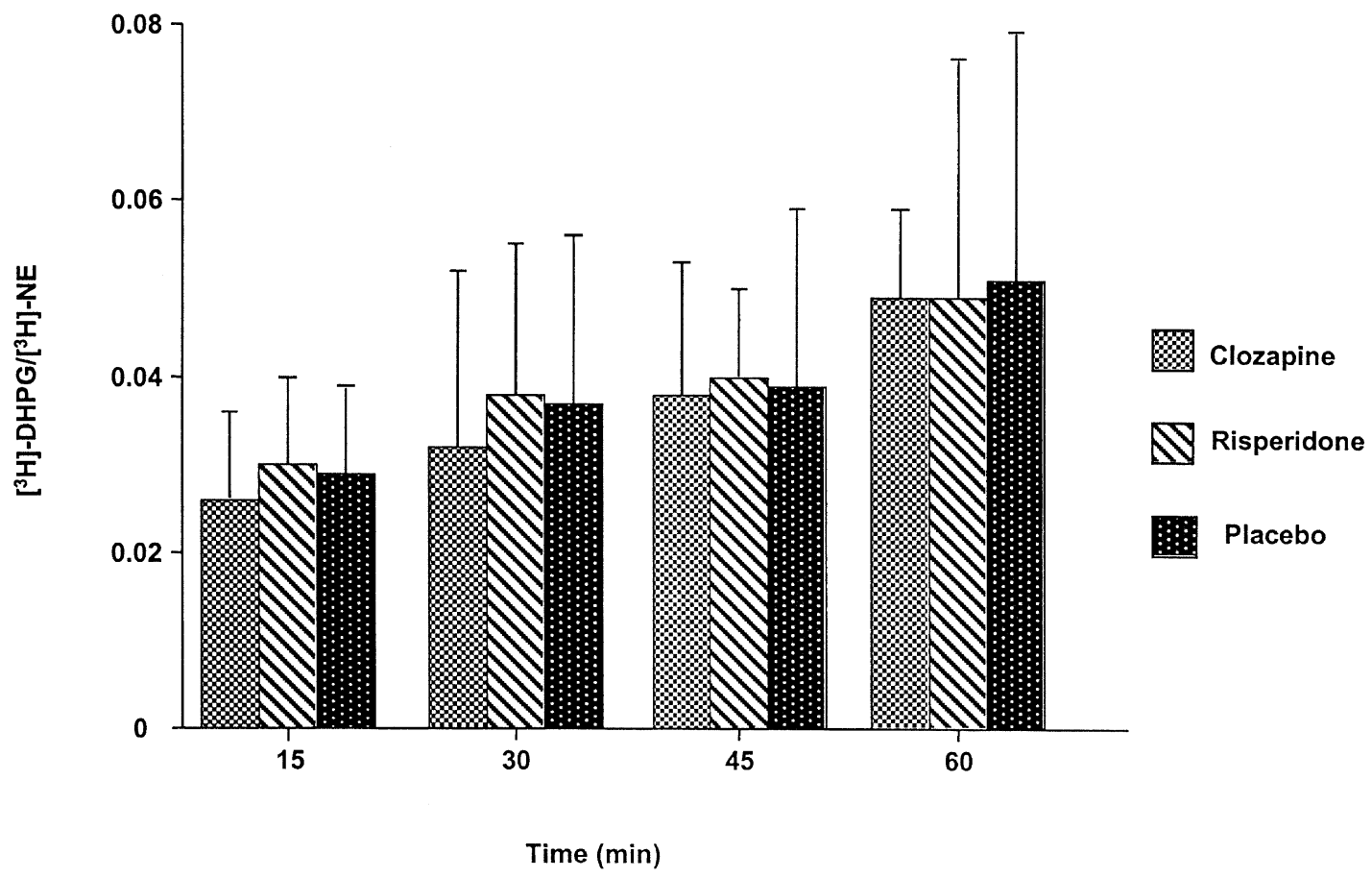

Figure 2. ${ }^{3} \mathrm{H}-\mathrm{DHPG} /{ }^{3} \mathrm{H}-\mathrm{NE}$ ratio in schizophrenic patients treated with clozapine $(\mathrm{n}=12)$, risperidone $(\mathrm{n}=8)$, and placebo $(n=6)$. Data are presented as mean \pm SD. Time-related trends in ${ }^{3} \mathrm{H}-\mathrm{DHPG} /{ }^{3} \mathrm{H}-\mathrm{NE}$ ratios were examined by repeatedmeasures ANOVAs, with drug condition (risperidone, clozapine, and placebo) as the grouping factor and time (15, 30, 45, and $60 \mathrm{~min}$ ) as the within-subjects factor. 
pine-induced sympathetic stimulation (Elman et al. 1999), we hypothesized that this mechanism would have more prominence in risperidone-treated patients because of risperidone's high affinity for $\alpha_{2}$ adrenoceptors (Schotte et al. 1993). Despite this, we observed substantial increases in plasma NE in patients treated with risperidone without corresponding changes in DHPG, as compared with patients on placebo $(\mathrm{t}=0.89 ; \mathrm{df}=12 ; p=.40)$, leading us to conclude that (like clozapine) $\alpha_{2}$ blockade alone could not be the sole explanation for risperidone's noradrenergic effects (Nasif et al. 2000). This is because plasma DHPG levels generally parallel NE levels during sympathetic stimulation (caused by $\alpha_{2}$ blockade), because of increased reuptake of the released NE.

In this study, NE spillover was increased in risperidone-treated patients, although less dramatically than in those treated with clozapine. Several factors determine NE spillover, besides exocytotic release in response to sympathetic nerve traffic. Probably, the most important is neuronal reuptake. Estimates of the efficiency of reuptake of endogenously released NE range up to about $90 \%$ (Iversen 1973; Esler et al. 1990). Clearly, even a small amount of inhibition of reuptake would augment the amount of NE entering the plasma for a given rate of exocytotic release from the terminals. The finding of high plasma NE levels in patients treated with risperidone without a corresponding increase in plasma DHPG would suggest that impaired NE reuptake might be involved in the NE increase, because plasma DHPG reflects the metabolism of axoplasmic NE (Goldstein et al. 1988; Goldstein 1995). All other things being the same, decreased reuptake of NE would increase NE spillover but decrease plasma DHPG levels. Moreover, risperidone has been demonstrated in preclinical studies to exert some degree of NE uptake inhibition (Leysen et al. 1988; Yoshimura et al. 2000). Thus, in this study, we explored the issue of possible neuronal uptake blockade by risperidone.

Neuronal reuptake contributes to clearance of circulating NE in humans (Esler et al. 1981; Eisenhofer et al. 1991). The present finding of no change in NE clearance in risperidone-treated patients compared with those on placebo argues against inhibition of neuronal uptake as a basis for high plasma NE levels in these patients. To examine neuronal uptake more specifically, we measured the arterial plasma ${ }^{3} \mathrm{H}-\mathrm{DHPG}$ response during ${ }^{3} \mathrm{H}-\mathrm{NE}$ infusion. Production of ${ }^{3} \mathrm{H}-\mathrm{DHPG}$ in patients on risperidone was similar to what was found in patients on placebo and those treated with clozapine, with or without correction of ${ }^{3} \mathrm{H}-\mathrm{DHPG}$ levels for concurrent plasma ${ }^{3} \mathrm{H}-\mathrm{NE}$ levels. As ${ }^{3} \mathrm{H}$-DHPG production in this setting results virtually exclusively from metabolism of ${ }^{3} \mathrm{H}-\mathrm{NE}$ in the sympathetic axoplasm (Goldstein et al. 1988; Goldstein 1995), the finding of normal ${ }^{3} \mathrm{H}-\mathrm{DHPG}$ and ${ }^{3} \mathrm{H}-\mathrm{DHPG} /{ }^{3} \mathrm{H}-\mathrm{NE}$ ratio responses would appear to eliminate decreased neuronal reuptake as the mechanism of high plasma NE levels in risperidone-treated patients.
A buildup of NE in the axoplasm, such as by inhibition of MAO and of the vesicular monoamine transporter, could increase NE release by a non-exocytotic process, via exit through the membrane transporter (Eisenhofer et al. 1986; Hovevey-Sion et al. 1990). The present finding of normal plasma levels of ${ }^{3} \mathrm{H}-\mathrm{DHPG}$ following ${ }^{3} \mathrm{H}-\mathrm{NE}$ infusion in risperidone-treated subjects renders MAO inhibition a highly unlikely mechanism of action of risperidone. Moreover, blockade of the vesicular monoamine transporter accelerates the rate of attainment of plateau ${ }^{3} \mathrm{H}-\mathrm{DHPG}$ concentrations during ${ }^{3} \mathrm{H}-\mathrm{NE}$ infusion (Eisenhofer et al. 1991), and in the present study risperidone treatment did not alter the slowly progressive increase in plasma ${ }^{3} \mathrm{H}$-DHPG levels.

Finally, although theoretically blockade of extraneuronal uptake of catecholamines or of the extraneuronal metabolizing enzyme catechol-O-methyltransferase could increase plasma NE levels for a given rate of entry into the interstitial fluid, too little of endogenously released $\mathrm{NE}$ undergoes extraneuronal uptake and enzymatic O-methylation to explain the two-fold increase in plasma NE levels in risperidone-treated subjects (Lenders et al. 1992; Lenders et al. 1993).

In conclusion, the pilot data presented here suggest that two second-generation APDs, risperidone and clozapine, share both similarities and differences with regard to their noradrenergic effects. Both drugs elevate plasma NE levels. Risperidone, as compared with clozapine, produces smaller elevations in arterial plasma NE secondary to lesser increases in NE spillover. At the same time DHPG levels tend to increase in risperidoneand to decrease in clozapine-treated patients. Differences in other indices of the noradrenergic system such as NE clearance, reuptake, and synthesis as well as MAO activity are not obvious. These data call for further research aimed at understanding the distinctive features of clozapine's noradrenergic effects vis-à-vis those of risperidone and their potential role in the drug's unique therapeutic profile.

\section{ACKNOWLEDGMENTS}

The authors gratefully acknowledge contributions of Katherine Karlsgodt, Jasmin Roman, Christopher Bir, Michael Wood, Lisa Picken, Jerry Rotter, the nursing staff of 4 East Clinical Care Unit, National Institutes of Health, and two anonymous reviewers. This research was supported by a grant to IE from the National Alliance on Research in Schizophrenia and Affective Disorders

\section{REFERENCES}

Ackenheil M (1989): Clozapine-pharmacokinetic investigations and biochemical effects in man. Psychopharmacology (Berl) 99:S32-S37 
Breier A (1994): Clozapine and noradrenergic function: support for a novel hypothesis for superior efficacy. J Clin Psychiatry 55(Suppl B):122-5

Breier A, Buchanan RW, Kirkpatrick B, Davis OR, Irish D, Summerfelt A, Carpenter WT Jr (1994a): Effects of clozapine on positive and negative symptoms in outpatients with schizophrenia. Am J Psychiatry 151:20-26

Breier A, Buchanan RW, Waltrip RW, Listwak S, Holmes C, Goldstein DS (1994b): The effect of clozapine on plasma norepinephrine: relationship to clinical efficacy. Neuropsychopharmacology 10:1-7

Breier A, Elman I, Goldstein DS (1998): Norepinephrine and schizophrenia: a new hypothesis for antipsychotic drug action. Adv Pharmacol 42:785-788

Breier A, Wolkowitz OM, Roy A, Potter WZ, Pickar D (1990): Plasma norepinephrine in chronic schizophrenia. Am J Psychiatry 147:1467-1470

Breier AF, Malhotra AK, Su TP, Pinals DA, Elman I, Adler CM, Lafargue RT, Clifton A, Pickar D (1999): Clozapine and risperidone in chronic schizophrenia: effects on symptoms, parkinsonian side effects, and neuroendocrine response. Am J Psychiatry 156:294-298

Brown AS, Gewirtz G, Harkavy-Friedman J, Cooper T, Brebion G, Amador XF, Malaspina D, Gorman JM (1997): Effects of clozapine on plasma catecholamines and relation to treatment response in schizophrenia: a withinsubject comparison with haloperidol. Neuropsychopharmacology 17:317-325

Campbell M, Young PI, Bateman DN, Smith JM, Thomas SH (1999): The use of atypical antipsychotics in the management of schizophrenia. Br J Clin Pharmacol 47:13-22

Chang PC, van der Krogt JA, Vermeij P, van Brummelen P (1986): Norepinephrine removal and release in the forearm of healthy subjects. Hypertension 8:801-809

Colli A, Cocciolo M, Francobandiera F, Rogantin F, Cattalini N (1999): Diabetic ketoacidosis associated with clozapine treatment. Diabetes Care 22:176-177

Croarkin PE, Jacobs KM, Bain BK (2000): Diabetic ketoacidosis associated with risperidone treatment? Psychosomatics 41:369-370

Davidson M, Kahn RS, Stern RG, Hirschowitz J, Apter S, Knott P, Davis KL (1993): Treatment with clozapine and its effect on plasma homovanillic acid and norepinephrine concentrations in schizophrenia. Psychiatry Res 46:151-163

Eisenhofer G, Esler MD, Meredith IT, Ferrier C, Lambert G, Jennings G (1991): Neuronal re-uptake of noradrenaline by sympathetic nerves in humans. Clin Sci (Colch) 80:257-263

Eisenhofer G, Friberg P, Rundqvist B, Quyyumi AA, Lambert G, Kaye DM, Kopin IJ, Goldstein DS, Esler MD (1996): Cardiac sympathetic nerve function in congestive heart failure. Circulation 93:1667-1676

Eisenhofer G, Goldstein DS, Stull R, Keiser HR, Sunderland T, Murphy DL, Kopin IJ (1986): Simultaneous liquidchromatographic determination of 3,4- dihydroxyphenylglycol, catecholamines, and 3,4-dihydroxyphenylalanine in plasma, and their responses to inhibition of monoamine oxidase. Clin Chem 32:2030-2033

Elman I, Goldstein DS, Eisenhofer G, Folio J, Malhotra AK, Adler CM, Pickar D, Breier A (1999): Mechanism of peripheral noradrenergic stimulation by clozapine. Neuropsychopharmacology 20:29-34

Esler M, Jackman G, Bobik A, Kelleher D, Jennings G, Leonard P, Skews H, Korner P (1979): Determination of norepinephrine apparent release rate and clearance in humans. Life Sci 25:1461-1470

Esler M, Jackman G, Leonard P, Skews H, Bobik A, Korner P (1981): Effect of norepinephrine uptake blockers on norepinephrine kinetics. Clin Pharmacol Ther 29:12-20

Esler M, Jennings G, Lambert G, Meredith I, Horne M, Eisenhofer G (1990): Overflow of catecholamine neurotransmitters to the circulation: source, fate, and functions. Physiol Rev 70:963-985

Esler M, Lambert G, Jennings G, Turner A, Kaye D (1998): Central and peripheral norepinephrine kinetics in heart failure, coronary artery disease, and hypertension. Adv Pharmacol 42:650-653

Fleischhaker C, Schulz E, Remschmidt H (1998): Biogenic amines as predictors of response to clozapine treatment in early-onset schizophrenia. J Psychiatr Res 32:325-333

Folkow B, Di Bona GF, Hjemdahl P, Toren PH, Wallin BG (1983): Measurements of plasma norepinephrine concentrations in human primary hypertension. A word of caution on their applicability for assessing neurogenic contributions. Hypertension 5:399-403

Friedman JI, Adler DN, Davis KL (1999a): The role of norepinephrine in the pathophysiology of cognitive disorders: potential applications to the treatment of cognitive dysfunction in schizophrenia and Alzheimer's disease. Biol Psychiatry 46:1243-1252

Friedman JI, Temporini H, Davis KL (1999b): Pharmacologic strategies for augmenting cognitive performance in schizophrenia. Biol Psychiatry 45:1-16

Goff DC, Evins AE (1998): Negative symptoms in schizophrenia: neurobiological models and treatment response. Harv Rev Psychiatry 6:59-77

Goldstein D (1995): Stress, Catecholamines, and Cardiovascular Disease. New York, Oxford University Press

Goldstein DS, Eisenhofer G, Stull R, Folio CJ, Keiser HR, Kopin IJ (1988): Plasma dihydroxyphenylglycol and the intraneuronal disposition of norepinephrine in humans. J Clin Invest 81:213-220

Goldstein DS, Udelsman R, Eisenhofer G, Stull R, Keiser HR, Kopin IJ (1987): Neuronal source of plasma dihydroxyphenylalanine. J Clin Endocrinol Metab 64:856-861

Green AI, Alam MY, Sobieraj JT, Pappalardo KM, Waternaux C, Salzman C, Schatzberg AF, Schildkraut JJ (1993): Clozapine response and plasma catecholamines and their metabolites. Psychiatry Res 46:139-149

Hovevey-Sion D, Eisenhofer G, Kopin IJ, Kirk KL, Chang PC, Szemeredi K, Goldstein DS (1990): Metabolic fate of injected radiolabelled dopamine and 2-fluorodopamine in rats. Neuropharmacology 29:881-887

Iversen LL (1973): Catecholamine uptake processes. Br Med Bull 29:130-135

Jimerson DC, Nurnberger JI Jr, Post RM, Gershon ES, Kopin IJ (1981): Plasma MHPG in rapid cyclers and healthy twins. Arch Gen Psychiatry 38:1287-1290

Kane J, Honigfeld G, Singer J, Meltzer H (1988): Clozapine for the treatment-resistant schizophrenic. a double-blind 
comparison with chlorpromazine. Arch Gen Psychiatry 45:789-796

Kane JM, McGlashan TH (1995): Treatment of schizophrenia. Lancet 346:820-825

Klimek V, Rajkowska G, Luker SN, Dilley G, Meltzer HY, Overholser JC, Stockmeier CA, Ordway GA (1999): Brain noradrenergic receptors in major depression and schizophrenia. Neuropsychopharmacology 21:69-81

Lambert GW, Thompson JM, Turner AG, Cox HS, Wilkinson D, Vaz M, Kalff V, Kelly MJ, Jennings GL, Esler MD (1997): Cerebral noradrenaline spillover and its relation to muscle sympathetic nervous activity in healthy human subjects. J Auton Nerv Syst 64:57-64

Lenders JW, Eisenhofer G, Armando I, Keiser HR, Goldstein DS, Kopin IJ (1993): Determination of metanephrines in plasma by liquid chromatography with electrochemical detection. Clin Chem 39:97-103

Lenders JW, Willemsen JJ, Beissel T, Kloppenborg PW, Thien T, Benraad TJ (1992): Value of the plasma norepinephrine/3,4-dihydroxyphenylglycol ratio for the diagnosis of pheochromocytoma. Am J Med 92:147-152

Leysen JE, Gommeren W, Eens A, de Chaffoy de Courcelles D, Stoof JC, Janssen PA (1988): Biochemical profile of risperidone, a new antipsychotic. J Pharmacol Exp Ther 247:661-70.

Lieberman J, Johns C, Cooper T, Pollack S, Kane J (1989): Clozapine pharmacology and tardive dyskinesia. Psychopharmacology (Berl) 99:S54-S59

Lieberman J, Johns C, Pollack S, Masiar S, Bookstein P, Cooper T, Iadorola M, Kane J (1991): Biochemical effects of clozapine in cerebrospinal fluid of patients with schizophrenia: advances in neuropsychiatry and psychopharmacology. Schizophr Res 1:341-349

Litman RE, Su TP, Potter WZ, Hong WW, Pickar D (1996): Idazoxan and response to typical neuroleptics in treatment-resistant schizophrenia. Comparison with the atypical neuroleptic, clozapine. Br J Psychiatry 168:571-579

Meltzer HY (1995): Clozapine: is another view valid? Am J Psychiatry 152:821-825

Meltzer HY, Thompson PA, Lee MA, Ranjan R (1996): Neuropsychologic deficits in schizophrenia: relation to social function and effect of antipsychotic drug treatment. Neuropsychopharmacology 14:27S-33S

Nagai N, Nagai K, Takezawa K, Chun SJ, Nakagawa H (1995): Suppressive effect of vasopressin on the hyperglycemic response to intracranial injection of 2-deoxyD-glucose. Neurosci Lett 190:187-190

Nasif FJ, Cuadra GR, Ramirez OA (2000): Effects of chronic risperidone on central noradrenergic transmission. Eur J Pharmacol 394:67-73

Pickar D (1995): Prospects for pharmacotherapy of schizophrenia. Lancet 345:557-562

Pickar D, Owen RR, Litman RE, Konicki E, Gutierrez R, Rapaport MH (1992): Clinical and biologic response to clozap- ine in patients with schizophrenia. Crossover comparison with fluphenazine. Arch Gen Psychiatry 49:345-353

Rao ML, Moller HJ (1994): Biochemical findings of negative symptoms in schizophrenia and their putative relevance to pharmacologic treatment. A review. Neuropsychobiology 30:160-172

Richelson E (1999): Receptor pharmacology of neuroleptics: relation to clinical effects. J Clin Psychiatry 60:5-14

Schotte A, Janssen PF, Megens AA, Leysen JE (1993): Occupancy of central neurotransmitter receptors by risperidone, clozapine and haloperidol, measured ex vivo by quantitative autoradiography. Brain Res 631:191-202

Schulz E, Fleischhaker C, Remschmidt HE (1996): Correlated changes in symptoms and neurotransmitter indices during maintenance treatment with clozapine or conventional neuroleptics in adolescents and young adults with schizophrenia. J Child Adolesc 6(2):119-131

Schulz E, Fleischhaker C, Clement HW, Remschmidt H (1997): Blood biogenic amines during clozapine treatment of early-onset schizophrenia. J Neural Transm 104:1077-1089

See RE, Fido AA, Maurice M, Ibrahim MM, Salama GM (1999): Risperidone-induced increase of plasma norepinephrine is not correlated with symptom improvement in chronic schizophrenia. Biol Psychiatry 45:1653-1656

Stahl SM (2000): Essential Psychopharmacology: Neuroscientific Basis and Practical Applications, ed 2. Cambridge, Cambridge University Press

Stein L, Wise CD (1971): Possible etiology of schizophrenia: progressive damage to the noradrenergic reward system by 6-hydroxydopamine. Science 171:1032-1036

Sternberg DE (1984): Biologic tests in psychiatry. Psychiatr Clin North Am 7:639-650

Tjurmina OA, Goldstein DS, Palkovits M, Kopin IJ (1999): Alpha2-adrenoceptor-mediated restraint of norepinephrine synthesis, release, and turnover during immobilization in rats. Brain Res 826:243-252

Walters JM, Ward GM, Barton J, Arackal R, Boston RC, Best JD, Alford FP (1997): The effect of norepinephrine on insulin secretion and glucose effectiveness in non-insulin-dependent diabetes. Metabolism 46:1448-1453

Yamamoto K, Ozawa N, Shinba T, Hoshino T, Yoshii M (1994): Possible noradrenergic dysfunction in schizophrenia. Brain Res Bull 35:529-543

Yoshimura R, Yanagihara N, Hara K, Terao T, Nakamura J, Ueno S, Toyohira Y, Uezono Y, Kaneko S, Kawamura M, Abe K, Izumi F (2000): Inhibitory effects of clozapine and other antipsychotic drugs on noradrenaline transporter in cultured bovine adrenal medullary cells. Psychopharmacology (Berl) 149:17-23

Ziegler MG, Lake CR, Wood JH, Brooks BR, Ebert MH (1977): Relationship between norepinephrine in blood and cerebrospinal fluid in the presence of a blood-cerebrospinal fluid barrier for norepinephrine. J Neurochem 28:677-679 